\title{
The relation between estimated glomerular filtration rate (eGFR) and coffee consumption in the Japanese
}

\author{
Nobuyuki Miyatake $^{1 *}$, Kenichi Shikata ${ }^{2,3}$, Hirofumi Makino ${ }^{3}$, Takeyuki Numata $^{4}$ \\ ${ }^{1}$ Department of Hygiene, Faculty of Medicine, Kagawa University, Kagawa, Japan; \\ ${ }^{*}$ Corresponding Author: miyarin@med.kagawa-i.ac.jp \\ ${ }^{2}$ Center for Innovative Medicine, Okayama University Hospital, Okayama, Japan; \\ ${ }^{3}$ Department of Medicine and Clinical Science, Okayama University Graduate School of Medicine, Dentistry and Pharmaceutical \\ Sciences, Okayama, Japan; \\ ${ }^{4}$ Okayama Southern Institute of Health, Okayama Health Foundation, Okayama, Japan.
}

Received August $10^{\text {th }}, 2011$; revised August $26^{\text {th }}, 2011$; accepted September $5^{\text {th }}, 2011$.

\begin{abstract}
We investigated the link between estimated glomerular filtration rate (eGFR) and coffee consumption in Japanese. We used data of 376 men and 794 women who were not taking any medications, aged 20 - 78 years, in this crosssectional investigation study. eGFR was calculated using serum creatinine (Cr), age and sex. Habitual coffee consumption was defined as drinking one or more cups of coffee per day. Two hundred thirty three men (62.0\%) and 400 women $(50.4 \%)$ were subjects with habitual coffee consumption (coffee consumption 1 cup/ day $\geq$ ). eGFR was negatively correlated with age (men: $r=-0.533$, women: $r=-624)$. eGFR in subjects with coffee consumers was not significantly different from that in subjects without coffee consumers after adjusting for age in both sexes (men: $p=0.1375$, women: $p=0.2069$ ). Among Japanese not taking medications, coffee consumption was not associated with eGFR in the Japanese population.
\end{abstract}

Keywords: Estimated Glomerular Filtration Rate (eGFR); Coffee Consumption; Creatinine; Japanese

\section{INTRODUCTION}

Coffee is one of the most common frequently consumed beverages and 10.6 coffee cups per week are reported to be consumed [1] and about $50 \%$ of Japanese drinks coffee daily [2]. Some studies showed that habitual coffee consumption may improve insulin resistance and abdominal glucose metabolism [3-5]. However, To- fovic et al. [6] have reported that prolonged consumption of caffeine has adverse effects on renal function, in high-renin hypertension.

Chronic kidney disease (CKD) has become a public health challenge and is a common disorder [7]. For example, about $20 \%$ of adults have CKD, which is defined as kidney damage or a glomerular filtration rate (GFR) < $60 \mathrm{ml} / \mathrm{min} / 1.73 \mathrm{~m}^{2}$ for at least three months regardless of cause [8]. We have also previously reported in a crosssectional study that the estimated glomerular filtration rate (eGFR) [9] in men with abdominal obesity and in women with hypertension was significantly lower than that in subjects without these components of metabolic syndrome [10]. Therefore, the effect of coffee consumption on renal function may be required and it still remains to be investigated in Japanese.

In this study, we investigated renal function evaluated by eGFR in Japanese and evaluated the clinical impact of coffee consumption on eGFR in subjects not taking medications.

\section{SUBJECTS AND METHODS}

\subsection{Subjects}

We used all data on 1170 Japanese (376 men and 794 women) aged 20-78 years in a cross-sectional study. All subjects met the following criteria: 1) they had wanted to change their lifestyle i.e. diet and exercise habits, and had received an annual health checkup from April 2006 to December 2010 at Okayama Southern Institute of Health; 2) they had received creatinine (Cr), anthropometric measurements and evaluation of coffee consumption as part of their annual health checkups; and 3) they provided informed consent (Table 1).

The study was approved by the Ethics Committee of Okayama Health Foundation. 
Table 1. Clinical profiles of enrolled subjects.

\begin{tabular}{|c|c|c|c|c|c|c|}
\hline & \multicolumn{3}{|c|}{ Men } & \multicolumn{3}{|c|}{ Women } \\
\hline & Mean \pm SD & Minimum & Maximum & Mean \pm SD & Minimum & Maximum \\
\hline Number of subjects & 376 & & & 794 & & \\
\hline Age & $42.7 \pm 13.2$ & 20 & 74 & $40.6 \pm 14.5$ & 20 & 78 \\
\hline Height (cm) & $170.3 \pm 6.1$ & 143.7 & 186.7 & $157.4 \pm 5.3$ & 140.5 & 172.9 \\
\hline Body weight (kg) & $71.3 \pm 11.7$ & 42.0 & 120.3 & $54.4 \pm 8.5$ & 29.3 & 113.9 \\
\hline Body mass index $\left(\mathrm{kg} / \mathrm{m}^{2}\right)$ & $24.6 \pm 3.6$ & 14.6 & 41.8 & $22.0 \pm 3.3$ & 14.1 & 44.9 \\
\hline Abdominal circumference $(\mathrm{cm})$ & $85.3 \pm 10.1$ & 60.5 & 122.0 & $75.7 \pm 9.8$ & 55.1 & 120.0 \\
\hline Hip circumference $(\mathrm{cm})$ & $95.7 \pm 8.4$ & 74.5 & 193.4 & $92.0 \pm 7.0$ & 70.0 & 196.5 \\
\hline Systolic blood pressure (mmHg) & $127.4 \pm 13.8$ & 94.0 & 191.0 & $114.7 \pm 15.6$ & 85.0 & 192.0 \\
\hline Diastolic blood pressure (mmHg) & $75.9 \pm 10.9$ & 50.0 & 112.0 & $67.0 \pm 10.9$ & 40.0 & 111.0 \\
\hline Creatinine (mg/dl) & $0.84 \pm 0.12$ & 0.51 & 1.34 & $0.62 \pm 0.09$ & 0.29 & 1.00 \\
\hline eGFR (ml/min/1.73 m²) & $83.2 \pm 15.5$ & 41.0 & 139.7 & $88.8 \pm 18.2$ & 42.5 & 172.9 \\
\hline Coffee consumption (cup/week) & $9.5 \pm 8.5$ & 0 & 40 & $7.5 \pm 7.9$ & 0 & 50 \\
\hline
\end{tabular}

\subsection{Anthropometric Measurements}

The anthropometric parameters were evaluated by using the following respective parameters such as height, body weight, body mass index (BMI), abdominal circumference, and hip circumference. BMI was calculated by weight/[height] ${ }^{2}\left(\mathrm{~kg} / \mathrm{m}^{2}\right)$. The abdominal circumference was measured at the umbilical level and the hip was measured at the widest circumference over the trochanter in standing subjects after normal expiration [11].

\subsection{Blood Pressure Measurements}

Each participant's blood pressure was measured after resting at least 15 minutes in the sitting position.

\subsection{Blood Sampling and Assays}

The level of $\mathrm{Cr}$ was measured with an automated biochemical analyzer (model 7700; HITACHI, Tokyo, Japan) and Accuras Auto CRE (Shino-Test Corporation, Tokyo, Japan) at the Okayama Southern Institute of Health, Okayama Health Foundation. eGFR was calculated using the following equation: eGFR $(\mathrm{ml} / \mathrm{min} / 1.73$ $\left.\mathrm{m}^{2}\right)=194 \times \mathrm{Cr}^{-1.094} \times \mathrm{Age}^{-0.287}$ (for men) and eGFR $(\mathrm{ml} /$ $\mathrm{min} / 1.73 \mathrm{~m}^{2}$ ) $=194 \times \mathrm{Cr}^{-1.094} \times \mathrm{Age}^{-0.287} \times 0.739$ (for women) [9]. Reduced eGFR was defined as an eGFR < $60 \mathrm{ml} / \mathrm{min} / 1.73 \mathrm{~m}^{2}$.

\subsection{Coffee Consumption}

Subjects were asked how many cups of coffee per week. They were dichotomized into coffee consumers who drink one or more cups of coffee per day, and non-coffee consumers who seldom drink coffee. The way of drinking was not asked.

\subsection{Statistical Analysis}

Data are expressed as means \pm standard deviation (SD) values. A comparison of parameters between the two groups was made using the unpaired $t$-test and covariance analysis. Simple correlation analysis was performed as well to test for the significance of the linear relationship among continuous variables: $p<0.05$ was considered statistically significant.

\section{RESULTS}

The mean eGFR was $83.2 \pm 15.5 \mathrm{ml} / \mathrm{min} / 1.73 \mathrm{~m}^{2}$ in men and $88.8 \pm 18.2 \mathrm{ml} / \mathrm{min} / 1.73 \mathrm{~m}^{2}$ in women (Table 1). The mean coffee consumption was $9.5 \pm 8.5 \mathrm{cups} /$ week/person in men and $7.5 \pm 7.9 \mathrm{cups} /$ week/person. A diagnosis of reduced eGFR was made for 19 men $(5.1 \%)$ and 27 women (3.4\%). eGFR was negatively correlated with age in either sex (Figure 1).

We clarified the prevalence of subjects with coffee consumers among subjects who were not taking without medications (Table 2). Among the 1,170 Japanese subjects, 233 men (62.0\%) and 400 women (50.4\%) were coffee consumers (coffee consumption 1 cup/day $\geq$ ). The prevalence of coffee consumers was the highest in 50's in men and 70's in women.

In subjects not taking medications, we also compared eGFR levels between the groups with and without coffee 
consumers of the Japanese (Table 3). To avoid the influence of age, we used age as a covariate and compared eGFR between Japanese with and without coffee consumers using covariance analysis. The significant difference of eGFR was not noted between subjects with and without coffee consumers, even after adjusting for age.

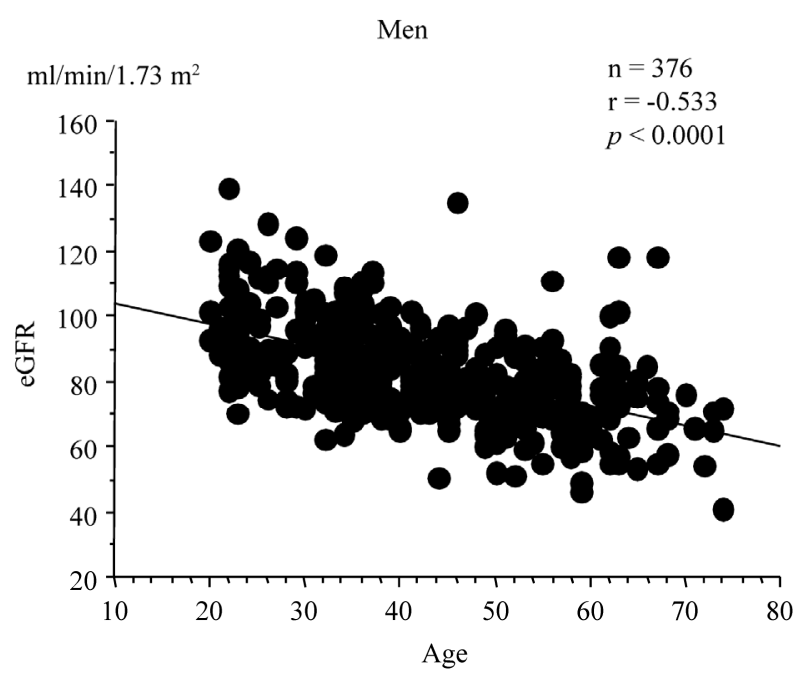

\section{DISCUSSION}

We firstly evaluated the link between eGFR using newly developed in Japan and coffee consumption in Japanese without taking any medications. The difference of eGFR was not noted between subjects with and without coffee consumers.

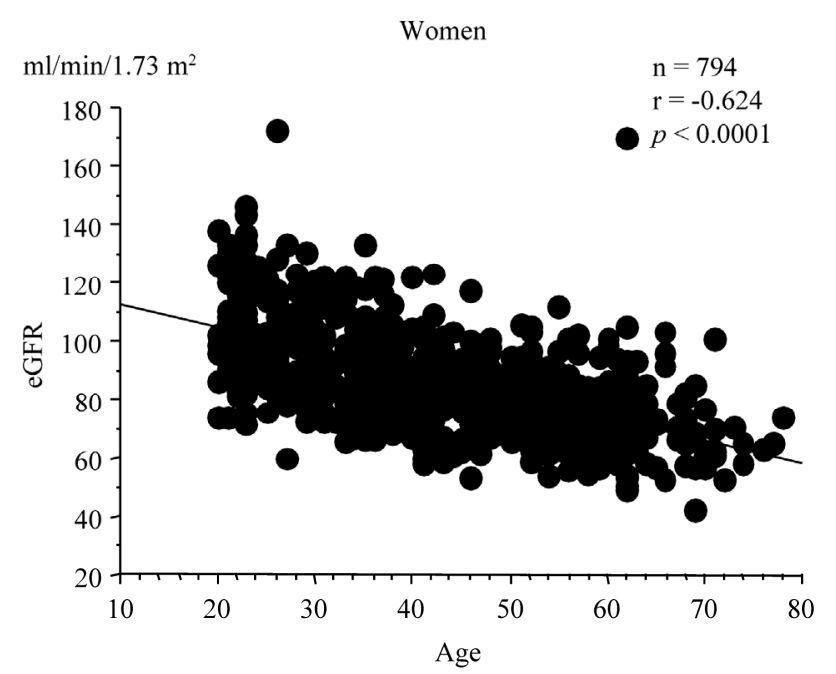

Figure 1. Simple correlation analysis between estimated glomerular filtration rate (eGFR) and age.

Table 2. Coffee consumption as classified by age groups.

\begin{tabular}{cccccccc}
\hline & $20-29$ & $30-39$ & $40-49$ & $50-59$ & $60-69$ & $70-$ & Total \\
\hline Men & & & & & & & \\
Coffee consumption 1 cup/day $<$ & $44(65.7)$ & $37(35.9)$ & $32(37.6)$ & $16(21.6)$ & $12(30.0)$ & $2(28.6)$ & $143(38.0)$ \\
Coffee consumption 1 cup/day $\geq$ & $23(34.3)$ & $66(64.1)$ & $53(62.4)$ & $58(78.4)$ & $28(70.0)$ & $5(71.4)$ & $233(62.0)$ \\
Men & & & & & & $4(26.7)$ & $394(49.6)$ \\
Coffee consumption 1 cup/day $<$ & $206(85.4)$ & $73(48.0)$ & $37(23.0)$ & $45(32.4)$ & $29(33.7)$ & $11(73.3)$ & $400(50.4)$ \\
Coffee consumption 1 cup/day $\geq$ & $35(14.5)$ & $79(52.0)$ & $124(77.0)$ & $94(67.6)$ & $57(66.3)$ & 1134
\end{tabular}

Number of subjects (\%).

Table 3. Comparison of eGFR between subjects as classified by coffee consumption.

\begin{tabular}{|c|c|c|c|c|}
\hline & Coffee consumption 1 cup/day $<$ & Coffee consumption 1 cup/day $\geq$ & $p$ & $p$ (After adjusting for age) \\
\hline \multicolumn{5}{|l|}{ Men } \\
\hline Number of subjects & 143 & 233 & & \\
\hline Age & $38.8 \pm 13.7$ & $45.1 \pm 12.4$ & $<0.0001$ & \\
\hline $\operatorname{eGFR}\left(\mathrm{ml} / \mathrm{min} / 1.73 \mathrm{~m}^{2}\right)$ & $86.5 \pm 16.5$ & $81.1 \pm 14.4$ & 0.0009 & 0.1375 \\
\hline \multicolumn{5}{|l|}{ Women } \\
\hline Number of subjects & 394 & 400 & & \\
\hline Age & $34.5 \pm 14.3$ & $46.6 \pm 12.1$ & $<0.0001$ & \\
\hline $\operatorname{eGFR}\left(\mathrm{ml} / \mathrm{min} / 1.73 \mathrm{~m}^{2}\right)$ & $94.1 \pm 19.0$ & $83.6 \pm 15.9$ & $<0.0001$ & 0.2069 \\
\hline
\end{tabular}

Mean \pm SD 
Iso et al. [2] reported that consumption of green tea, coffee, and total caffeine was associated with a risk for type 2 diabetes in 17,413 subjects with 5-year follow-up. Multivariable odds ratio for diabetes among participants who frequently drank coffee ( 3 cups of coffee per day $\geq$ ) was 0.58 , respectively, compared with those who drank less than 1 cup per week. According to the link between habitual coffee consumption and eGFR in Japanese, Nakajima et al. [12] reported that eGFR in coffee consumers $(n=182)$ was significantly higher than that in non-coffee consumers $(n=160)$, which was not attenuated even after adjustment for age, sex and considerable factors. Kotani et al. [13] also reported that coffee drinkers had higher eGFR values than non-coffee drinkers in 114 Japanese. The difference remained significant, independently of clinical variables. However, in this study, we could not found the significant difference of eGFR between subjects with and without habitual coffee consumption. Compared the previous studies, the age enrolled in this study was younger. In addition, the age in subjects with habitual coffee consumption was significantly higher than that in subjects without in this study. Enrolled subjects in this study were taking no medications, suggesting apparently healthy subjects. Prolonged caffeine consumption has adverse effects on renal function in rats [6]. Therefore, the results may not be similar to previous reports.

Potential limitations remain in this study. First, our study was a cross sectional and not a longitudinal study. Second, the 1170 subjects, all of whom wanted to change their lifestyle, underwent measurements for this study: they were therefore more health-conscious than the average person. Second, we could not clarify the mechanism the link between eGFR and coffee consumption. Third, the coffee consumption was reported to be $10.6 \mathrm{cups} / \mathrm{week} /$ person in 2008 , and it is the highest between 40 and 59 (men: 13.5 cups/week/person, women: 14.2 cups/week/person) in Japanese by All Japan Coffee Association [1]. The coffee consumption was gradually increasing [1]. In this study, the mean of the coffee consumption was lower than that in the previous report. Further prospective studies are needed in Japanese subjects using the new Japanese criteria.

\section{ACKNOWLEDGEMENTS}

This research was supported in part by Research Grants from the Ministry of Health, Labor, and Welfare, Japan.

\section{REFERENCES}

[1] All Japan Coffee Association (2011). http://coffee.ajca.or.jp/data/pdf/2010-04.pdf

[2] Iso, H., Date, C., Wakai, K., Fukui, M., Tamakoshi, A., JACC Study Group. (2006) The relationship between green tea and total caffeine intake and risk for self-reported type 2 diabetes among Japanese adults. Annals of Internal Medicine, 144, 554-562.

[3] Van Dam, R.M. (2008) Coffee consumption and risk of type 2 diabetes, cardiovascular diseases, and cancer. Applied Physiology, Nutrition, and Metabolism, 33, 12691283. doi:10.1139/H08-120

[4] Greenberg, J.A., Boozer, C.N. and Geliebter, A. (2006) Coffee, diabetes, and weight control. The American Journal of Clinical Nutrition, 84, 682-693.

[5] Tunnicliffe, J.M. and Shearer, J. (2008) Coffee, glucose homeostasis, and insulin resistance: Physiological mechanisms and mediators. Applied Physiology, Nutrition, and Metabolism, 33, 1290-1300. doi: 10.1139/H08-123

[6] Tofovic, S.P. and Jackson, E.K. (1999) Effects of long-term caffeine consumption on renal function in spontaneously hypertensive heart failure prone rats. Journal of Cardiovascular Pharmacology, 33, 360-366. doi:10.1097/00005344-199903000-00003

[7] National Kidney Foundation (2002) K/DOQI clinical practice guidelines for chronic kidney disease: Evaluation, classification, and stratification. Kidney Disease Outcome Quality Initiative. American Journal of Kidney Diseases, 39, S1-S266.

[8] Imai, E., Horio, M., Iseki, K., Yamagata, K., Watanabe, T., Hara, S., Ura, N., Kiyohara, Y., Hirakata, H., Moriyama, T., Ando, Y., Nitta, K., Inaguma, D., Narita, I., Iso, H., Wakai, K., Yasuda, Y., Tsukamoto, Y., Ito, S., Makino, H., Hishida, A. and Matsuo, S. (2007) Prevalence of chronic kidney disease (CKD) in the Japanese general population predicted by the MDRD equation modified by a Japanese coefficient. Clinical and Experimental Nephrology, 11, 156-163. doi:10.1007/s10157-007-0463-X

[9] Matsuo, S., Imai, E., Horio, M., Yasuda, Y., Tomita, K., Nitta, K., Yamagata, K., Tomino, Y., Yokoyama, H. and Hishida, A. (2009) Revised equations for estimated GFR from serum creatinine in Japan. American Journal of Kidney Diseases, 53, 982-992. doi:10.1053/j.ajkd.2008.12.034

[10] Miyatake, N., Shikata, K., Makino, H. and Numata, T. (2010) Relationship between Estimated Glomerular Filtration Rate (eGFR) and Metabolic Syndrome in the Japanese Population. Acta Medica Okayama, 64, 203-208.

[11] Anonym (2005) Definition and the diagnostic standard for metabolic syndrome-Committee to Evaluate Diagnostic Standards for Metabolic Syndrome. Nippon Naika Gakkai Zasshi, 94, 794-809. doi:10.2169/naika.94.794

[12] Nakajima, K., Hirose, K., Ebata, M., Morita, K. and Munakata, H. (2009) Association between habitual coffee consumption and normal or increased estimated glomerular filtration rate in apparently healthy adults. British Journal of Nutrition, 103, 149-152. doi:10.1017/S0007114509991681

[13] Kotani, K., Sakane, N., Yamada, T. and Taniguchi, N. (2010) Association between coffee consumption and the estimated glomerular filtration rate in the general Japanese population: Preliminary data regarding C-reactive protein concentration. Clinical Chemistry and Laboratory Medicine, 48, 1773-1776. doi:10.1515/CCLM.2010.347 